\title{
Resolution of the apparent experimental discrepancies observed between SVET and SECM for the characterization of galvanic corrosion reactions
}

\author{
J. Izquierdo' ${ }^{1}$, L. Nagy $^{2}$, S. González ${ }^{1}$, J.J. Santana ${ }^{3}$, G. Nagy², R.M. Souto ${ }^{1}$ \\ ${ }^{1}$ Department of Physical Chemistry, University of La Laguna, 38071 La Laguna, Tenerife, \\ Canary Islands, Spain. \\ 2 Department of General and Physical Chemistry, Faculty of Sciences, University of Pécs, \\ 7624 Pécs, Ifjúság útja 6, Hungary \\ ${ }^{3}$ Department of Process Engineering, University of Las Palmas de Gran Canaria, 35017 Las \\ Palmas de Gran Canaria, Canary Islands, Spain
}

\begin{abstract}
A new approach for studying the local distribution of anodic and cathodic sites in a corroding system using the scanning vibrating electrode technique (SVET) and scanning electrochemical microscopy (SECM) is presented. When zinc is coupled to iron, dissolution of the active metal occurs in a localized manner (e.g. pitting corrosion), allowing for cathodic sites to be developed on zinc. Local alkalization and oxygen consumption related to cathodic activity are detected above portions of the zinc surface using SECM. Anionic fluxes related to the generation of $\mathrm{OH}^{-}$ions could be measured on the zinc surface outside the corroding pit by rastering the SVET probe closer to the substrate.
\end{abstract}

Keywords: SVET; SECM; galvanic corrosion; concentration distributions; zinc; iron. 


\section{Introduction}

Application of scanning microelectrochemical techniques in Corrosion Science has contributed to a major advancement in the understanding of corrosion reactions because earlier stages of these processes have become available. Despite the differences in operating principles employed, their outcomes are usually complementary helping to gain new insights with spatial and electrochemical resolution [1,2]. Among them, the Scanning Vibrating Electrode Technique (SVET) is widely employed in corrosion laboratories [1], whereas scanning electrochemical microscopy (SECM) is gaining interest because its chemical selectivity [2].

SVET has been applied to the zinc-iron galvanic pair to investigate the effect of ambient parameters on the galvanic process [3], to screen the efficiency of corrosion inhibitors [4], and to characterize delamination effects from cut edges [5] or defects on coated galvanized steels [6]. Additionally, most of the SECM-based operation modes that are available for the characterization of corrosion processes have been validated using this model system, namely determination of concentration distributions from amperometric generation-collection operation [7], monitoring of oxygen with the redox competition mode [8], quantitative metal dissolution determination using tip modification and stripping voltammetry [9], local $\mathrm{pH}$ and ion-selective detection under potentiometric operation $[10,11]$. Though good agreement between the information provided by SVET and the new operation modes in SECM used to be the rule, some discrepancies have been discovered recently. They originate from the localized nature of the dissolution process occurring on zinc, and the new evidences of an extension of the cathodic activity to this metal.

In this work we report evidences of local cathodic activity on the more active metal within the zinc-iron galvanic couple detected using the new operation modes of SECM. The same features were monitored by SVET when operation conditions ensured greater spatial resolution.

\section{Experimental}

$99.5 \%$ purity iron and $99.95 \%$ purity zinc cut into square specimens of $1 \times 1 \mathrm{~mm}^{2}$ dimensions were mounted into an epoxy resin sleeve (dia. $4 \mathrm{~cm}$ ). The separation between the metals was ca. $1 \mathrm{~mm}$, and electric connection was made at the rear of the mount. The front side of the mounts was ground with silicon carbide paper down to 4000 grit and subsequently polished with $0.3 \mu \mathrm{m}$ alumina. The resulting surface was rinsed with Millipore deionized water and allowed to dry in air. The front side of the mount was placed upwards and surrounded laterally by Sellotape, thus creating a small container for the electrolyte solution. The electrochemical cells for SVET and SECM were completed with the inclusion of their corresponding microelectrodes. Testing was carried out in aqueous $0.01 \mathrm{M} \mathrm{NaCl}$ solution made from analytical grade reagent and Millipore deionized water. The solution was naturally aerated 
and experiments were conducted at ambient temperature.

The SVET instrument used in this work was manufactured by Applicable Electronics (New Haven, CT, USA). The vibrating probe was prepared from a Pt/Ir $(80 \% / 20 \%)$ wire insulated with paralene $C^{\circledR}$ and arced at the tip to expose the metal. The microelectrode was platinized in order to produce a spherical platinum black deposit of $20 \mu \mathrm{m}$ diameter. The measurements were made with the electrode tip vibrating in a plane perpendicular to the sample.

A home-built SECM system was employed [12]. For the potentiometric operation, a $10^{12} \Omega$ input impedance operational amplifier was introduced in the measuring circuit [11]. An antimony tip [10] was employed both as amperometric tip and $\mathrm{pH}$ sensor, having a $25 \mu \mathrm{m}$ diameter active disk surface and an RG value of about 5 . It exhibits a linear relationship between the potential and the solution $\mathrm{pH}$ in the $3<\mathrm{pH} \leq 11.5$ range, with slope $46.1 \mathrm{mV} / \mathrm{pH}$ unit. The SECM cell was completed with an $\mathrm{Ag} / \mathrm{AgCl} / \mathrm{KCl}(3 \mathrm{M})$ reference electrode, and a $\mathrm{Pt}$ wire as counter electrode for the amperometric measurements.

\section{Results and discussion}

Figure 1 shows the ionic current flows over a zinc/iron couple measured by SVET, closely matching previous reports [3]. The cathodic and anodic activities were well separated and located on iron and zinc, respectively, as anticipated in a galvanic couple with zinc oxidizing sacrificially and preventing the corrosion of iron. The ionic flows related to cathodic activity emerge from a large cathode that covers the complete surface of iron. They correspond to an upward flow of $\mathrm{OH}^{-}$anions produced in the reduction of dissolved oxygen:

$$
\mathrm{O}_{2}+\mathrm{H}_{2} \mathrm{O}+4 \mathrm{e}^{-} \rightarrow 4 \mathrm{OH}^{-}
$$

Accordingly, the amount of $\mathrm{O}_{2}$ in solution should be lower near this cathodic region, simultaneously to local alkalization of the electrolyte. Next, a small anode was observed on the zinc wire related to the development of one corrosion pit. Anodic currents were detected only above the pit corresponding to the flow of cations produced during the oxidation of zinc:

$$
\mathrm{Zn} \rightarrow \mathrm{Zn}^{2+}+2 \mathrm{e}^{-}
$$

$\mathrm{pH}$ changes also occur due to the hydrolysis of the metal ions:

$$
\mathrm{Zn}^{2+}+\mathrm{H}_{2} \mathrm{O} \stackrel{\mathrm{K}_{\mathrm{hyd}}^{1}}{\longrightarrow} \mathrm{Zn}(\mathrm{OH})^{+}+\mathrm{H}^{+}
$$

leading to weak acidification in the solution around the anodic sites [13].

The consumption of dissolved oxygen related to cathodic activity can be imaged in situ using the amperometric mode of the SECM, provided a sufficiently negative potential is applied to the antimony microelectrode (namely $-0.65 \mathrm{~V}$ vs. $\mathrm{Ag} / \mathrm{AgCl} / 3 \mathrm{M} \mathrm{KCl}$ ) [10]. Figure 2 displays a series of scan lines measured with the tip travelling above the centre of the two metals for 
different times. The first line recorded after 28 min depicts a region of depleted oxygen concentration extending over the dimensions of the iron sample, and the concentration steadily tends to the values in the bulk electrolyte when the tip is placed over the resin sleeve at both sides of the iron strip independently of the location of the zinc anode. But further excursion of the antimony tip above the zinc strip reveals another region of depleted oxygen concentration in the solution. With the elapse of time, the tip currents were even smaller, indicating that oxygen was consumed on both metals and it became exhausted from the adjacent electrolyte. In fact, at the largest exposure shown (i.e. $138 \mathrm{~min}$ ), oxygen concentration was almost the same above the two metals and the resin between them, and only increased beyond the two metal strips. Since the region of depleted oxygen above zinc had smaller dimensions that the zinc sample, the reduction of oxygen occurs outside the corroding pit.

The occurrence of localized cathodic activity on the zinc strip is also observed from Figure 3 , which gives the $\mathrm{pH}$ distribution map determined using potentiometric SECM. Though the electrolyte was slightly acidic originally due to carbonation of the aerated solution, alkalization is found over both metals. $\mathrm{pH}$ values around 10 are observed over a fraction of the zinc strip, whereas 1-2 units higher $\mathrm{pH}$ values are observed over the dimensions of iron. These results support that most cathodic activity occurred on the nobler metal in the galvanic couple, yet some measurable cathodic activity could be detected on zinc at those regions of the surface that did not undergo anodic oxidation.

To our knowledge, the features described here have not been reported in the scientific literature until now. Furthermore, they seem to be in conflict with the conclusions derived from images taken by SVET such as Figure 1. In order to detect some cathodic activity also on the zinc metal coupled to iron using SVET, the experimental procedure was modified in two ways. Firstly, smaller tip-sample distances were adopted. Usually, tip-sample distances in excess of $100 \mu \mathrm{m}$ are employed for vibrating probes of $20 \mu \mathrm{m}$ diameter to avoid artefacts originating from coupling currents [14], tip inclination [15], and large-amplitude vibrations [16], which severely hinder the accessibility of the limits predicted by the theory [17] (ideally equivalent to 1 tip diameter). Careful operation allowed a tip-substrate distance of $80 \mu \mathrm{m}$ to be used. Secondly, the electrochemical activity above each metal was recorded in separated images, to improve the detection of the highest and lowest ionic currents on each metal. The map measured above the zinc strip using SVET operated in these conditions is shown in Figure 4A. A large anodic activity is localized on the left half of the image, simultaneously to the occurrence of a significantly smaller cathodic activity on the remaining metal surface. The localization of the current flow related to the release of $\mathrm{Zn}^{2+}$ ions from the metal surface closely matches the position of the corrosion pit observed in the micrograph given in Figure $4 \mathrm{~B}$. Next, the unmodified portion of the surface outside the pit serves as corrosion sites for oxygen electroreduction with the generation 
of a small flow of $\mathrm{OH}^{-}$ions into the electrolyte solution. These results validate the previous observations obtained by SECM, thus resolving the apparent discrepancies observed between different scanning microelectrochemical techniques for the characterization of galvanic corrosion reactions.

\section{Conclusion}

Cathodic activity on the active metal in a zinc-iron pair has been detected using SECM and SVET. The localized nature of the anodic reaction of zinc, with the formation of corroding pits, leaves the remaining surface of the metal available for oxygen electroreduction by the electrons released by the oxidation of the metal. Changes on the oxygen concentration and the $\mathrm{pH}$ in the solution related to cathodic activity can be spatially resolved using a dual amperometric/potentiometric antimony microelectrode as the tip in SECM. The fluxes of the $\mathrm{OH}^{-}$ anions on both metals can be detected by SVET operated at short tip-substrate distances.

\section{Acknowledgments:}

This work has been supported by the Spanish Ministry of Science and Innovation and the European Regional Development Fund under Project No. CTQ2009-12459, and by "Developing Competitiveness of Universities in the South Transdanubian Region (SROP-4.2.1.B-10/2/KONV2010-0002)". A Research Training Grant awarded to J.I. by the Spanish Ministry of Education (Programa de Formación de Personal Investigador) is gratefully acknowledged.

\section{References}

1. Analytical Methods in Corrosion Science and Engineering (P. Marcus, F. Mansfeld, eds.). CRC Press, Boca Raton (2006).

2. M.B. Jensen, D.E. Tallman, in: Electroanalytical chemistry (A.J. Bard, C.G. Zoski, eds.). CRC Press, Boca Raton (2012), p. 171.

3. R.M. Souto, Y. González-García, A.C. Bastos, A.M. Simões, Corros. Sci. 49 (2007) 4568.

4. S. Kallip, A.C. Bastos, M.L. Zheludkevich, M.G.S. Ferreira, Corros. Sci. 52 (2010) 3146.

5. K. Ogle, S. Morel, D. Jacquet, J. Electrochem. Soc. 153 (2006) B1.

6. R.M. Souto, B. Normand, H. Takenouti, M. Keddam, Electrochim. Acta 55 (2010) 4551.

7. A.M. Simões, A.C. Bastos, M.G. Ferreira, Y. González-García, S. González, R.M. Souto, Corros. Sci. 49 (2007) 726. 
8. J.J. Santana, J. González-Guzmán, L. Fernández-Mérida, S. González, R.M. Souto, Electrochim. Acta 55 (2010) 4488.

9. R.M. Souto, Y. González-García, D. Battistel, S. Daniele, Corros. Sci. 55 (2012) 401.

10. J. Izquierdo, L. Nagy, Á. Varga, J.J. Santana, G. Nagy, R.M. Souto, Electrochim. Acta 56 (2011) 8846.

11. J. Izquierdo, L. Nagy, Á. Varga, I. Bitter, G. Nagy, R.M. Souto, Electrochim. Acta 59 (2012) 398.

12. B. Kovács, B. Csóka, G. Nagy, I. Kapui, R.E. Gyurcsányi, K. Tóth, Electroanalysis 11 (1999) 349.

13. S.V. Lamaka, R.M. Souto, M.G.S. Ferreira, in: Microscopy: Science, Technology, Applications and Education, Vol. 3 (A. Méndez-Vilas, J. Díaz, eds.). Formatex Research Center, Badajoz (2010), p. 2162.

14. N. Murer, R. Oltra, B. Vuillemin, O. Néel, Corros. Sci. 52 (2010) 130.

15. B.P. Wilson, J.R. Searle, K. Yliniemi, D.A. Worsley, H.N. McMurray, Electrochim. Acta 66 (2012) 52.

16. H.N. McMurray, D. Williams, D.A. Worsley, J. Electrochem. Soc. 150 (2003) B567.

17. H.S. Isaacs, J. Electrochem. Soc. 138 (1991) 722.
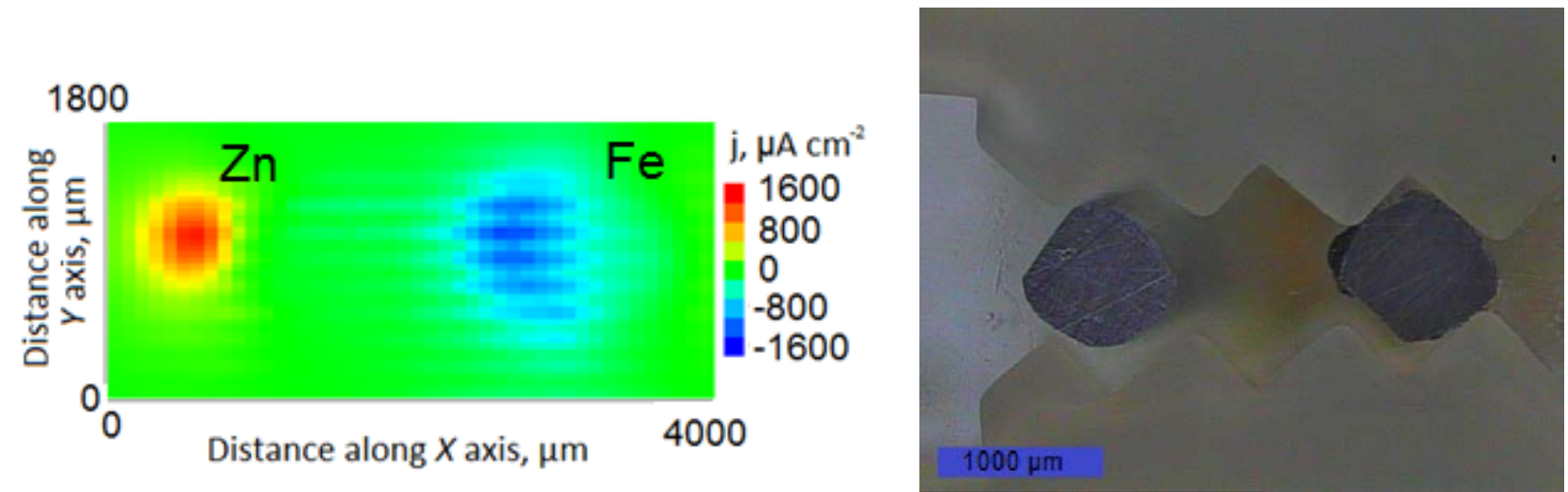

Figure 1 - Ionic current map (left) and video image (right) of a zinc-iron galvanic pair immersed in $0.01 \mathrm{M} \mathrm{NaCl}$. Tip-substrate distance: $150 \mu \mathrm{m}$. 


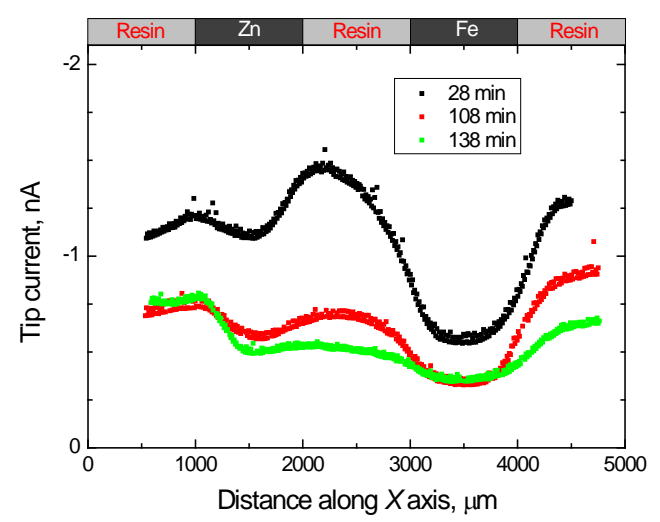

Figure 2 - Distribution of oxygen concentration above the zinc-iron galvanic couple in $0.01 \mathrm{M}$ $\mathrm{NaCl}$ measured by amperometric SECM using an antimony tip. $E_{t i p}=-0.65 \mathrm{~V} v \mathrm{vs} . \mathrm{Ag} / \mathrm{AgCl} / 3 \mathrm{M}$ $\mathrm{KCl}$; tip-substrate distance: $25 \mu \mathrm{m}$.

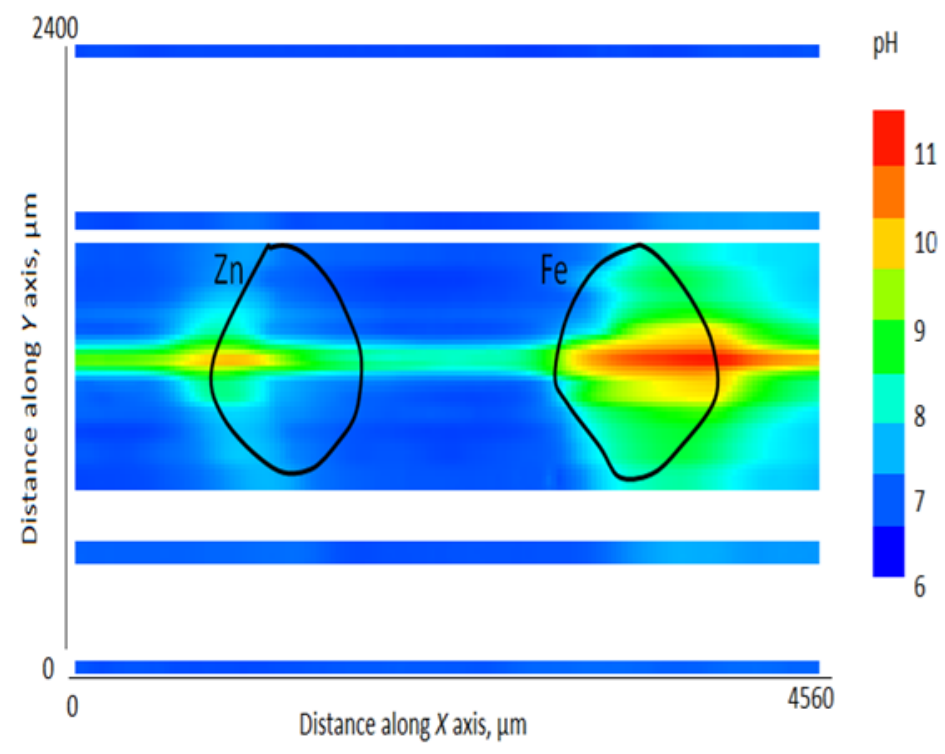

Figure 3 - Potentiometric SECM using the antimony tip to record the $\mathrm{pH}$ distribution in a plane parallel to the surface of the zinc-iron galvanic couple after immersion in $0.01 \mathrm{M} \mathrm{NaCl}$ for $4 \mathrm{~h}$. Tip-substrate distance: $25 \mu \mathrm{m}$.
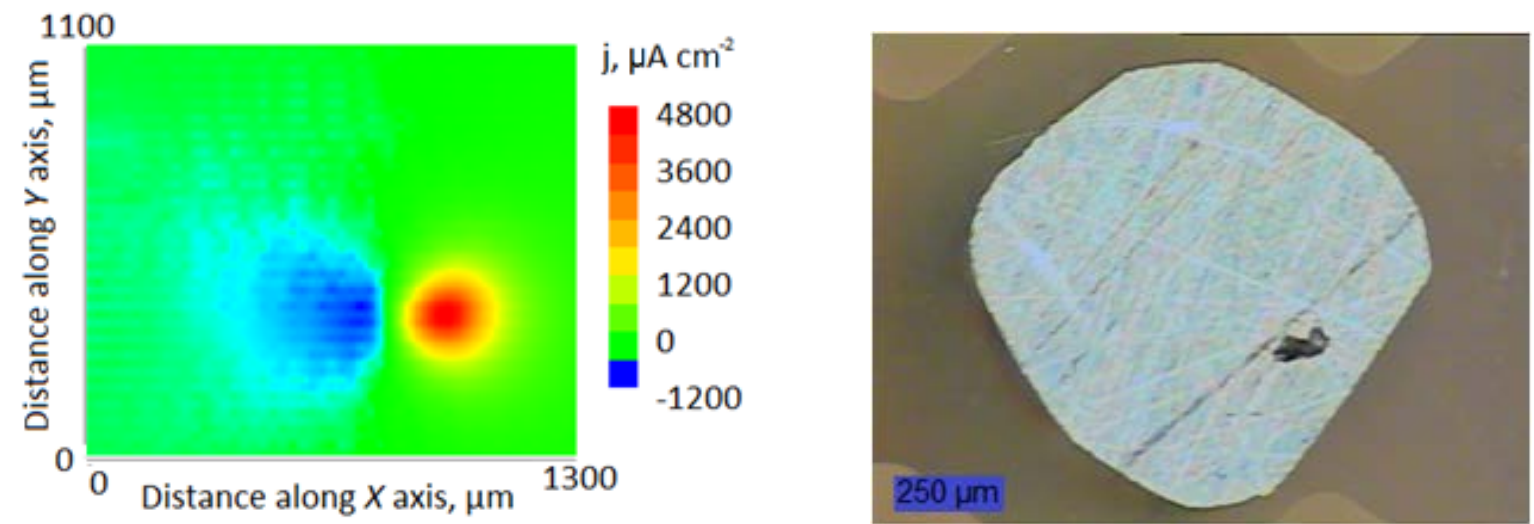

Figure 4 - Ionic current map (left) and video image (right) of the zinc sample in a zinc-iron galvanic pair immersed in $0.01 \mathrm{M} \mathrm{NaCl}$. Tip-substrate distance: $80 \mu \mathrm{m}$. 